\title{
Investigation of Association between Hepatitis B Virus Infection and Type 2 Diabetes Mellitus
}

\author{
Ilhan Sabancilar \\ Institute of Health Sciences, Dept. of Biochemistry, Dicle University \\ Sur 21280, Diyarbakir, Turkey \\ E-mail: ilhansabancilar@hotmail.com \\ Nida Ozcan (Corresponding author) \\ Faculty of Medicine, Dept.of Microbiology, Dicle University \\ Sur 21280, Diyarbakir, Turkey \\ E-mail: nida.ozcan@dicle.edu.tr \\ Belkis Aydinol \\ Faculty of Medicine, Dept.of Biochemistry, Dicle University \\ Sur 21280, Diyarbakir, Turkey \\ E-mail: b.aydinol@dicle.edu.tr \\ Tugba Gur \\ Institude of Health Sciences, Dept.of Biochemistry, Yuzuncu Yil University \\ Van, Turkey \\ E-mail: tugbagur80@gmail.com \\ Omer Satici \\ Faculty of Medicine, Dept.of Biostatistics, Dicle University \\ Sur 21280, Diyarbakir, Turkey \\ E-mail: omrs@dicle.edu.tr
}

No financial support was provided for this study.

\begin{abstract}
It was aimed to evaluate the relationship between diabetes and hepatitis B in patients with type 2 diabetes. This retrospective study was conducted between January 2012 and December 2017 in Dicle University Hospital. A total of 686 patients (344 male, 342 female) diagnosed with Type 2 Diabetes Mellitus (T2DM) (whose with HbA1c>6.5) were included. Alcohol users, patients who underwent dialysis and with frequent blood transfusions (such as thalassemia major or hemophilia) were excluded from the study. Patients were divided into two groups as those with hepatitis B (HBsAg $>1$ ) and those without hepatitis B $(\mathrm{HBsAg}<1)$. Age, gender and liver function tests of the patients were evaluated retrospectively and compared between the two groups. Pearson correlation coefficient was calculated between the variables. Student's t test was used to compare the two groups. Chi-square test was used for categorical variables.

In the HBsAg positive patient group; the relationship of HbsAg with Alanine Aminotransferase (ALT) and Aspartate Aminotransferase (AST) was significant $(p<0.05)$, also a statistically significant relationship was found between Hba1c elevation with ALT levels and age $(p<0.01)$. No statistically significant difference was found between HBsAg and HbAlc in HB patients group. There was no significant difference in AST and ALT levels between two groups.

Conclusion: There was no significant relationship between HB and T2DM in current retrospective study including T2DM patients.
\end{abstract}

Keywords: Hepatitis B Virus, Type 2 Diabetes Mellitus, Aspartate Aminotransferase, Alanine Aminotransferase 
DOI: $10.7176 / \mathrm{JSTR} / 5-10-10$

\section{Introduction}

Type 2 Diabetes Mellitus (T2DM) is a metabolic disorder associated with persistent hyperglycemia as a result of impaired glucose homeostasis. Impaired insulin secretion and/or resistance to peripheral effects of insulin are responsible for the pathogenesis of the disease(Goyal \& Jialal, 2019). It is estimated that 30.3 million people worldwide have diabetes, of which 7.2 million $(23.8 \%)$ have not yet been diagnosed (Centers for Disease Control and Prevention, 2017). Periodically monitoring of blood glucose levels from capillaries or venules are generally required in patients with diabetes. The transmission risk of bloodborne pathogens may occur during such percutaneous procedures. Hepatitis B (HB) is one of the leading blood-borne contagious diseases. Exposure to infected blood and other body fluids is a major way of spreading Hepatitis B virus (HBV). According to the World Health Organization (WHO) data, about 260 million people were estimated to have Hepatitis B surface antigen (HBsAg) positivity, and only \%10.5 of them were aware of their infection in 2016(World Health Organisation, 2019). In this study, it was aimed to examine the relationship between HB and T2DM, in which percutaneous interventions are frequently performed.

\section{Materials and Methods}

\subsection{Study Group}

This retrospective study was conducted between January 2012 and December 2017 in Dicle University Hospital. A total of 686 patients (344 male, 342 female) admitted to endocrinology outpatient clinics and diagnosed with Type 2 Diabetes Mellitus (T2DM) (whose with HbA1c>6.5) were included. Alcohol users, patients who underwent dialysis and with frequent blood transfusions (such as thalassemia major, hemophilia) were excluded from the study. Patients were divided into two groups as those with hepatitis B (HBsAg $>1)$ and those without hepatitis B (HBsAg <1).

\subsection{Analyses}

HBsAg, anti-HBs and anti- HBcIgG were studied by ELISA method with Cobas e 601 (Roche Diagnostics, Switzerland) system autoanalyzer. HBsAg value above 1 Cut Off Index (COI) was considered positive. Serum Aspartate Aminotransferase (AST) and Alanine Aminotransferase (ALT) levels were measured by Architect c8000 (Abbott, Illinois, USA) automated chemistry analyzer. Age and gender characteristics of the patients were retrospectively obtained from patient files.

\subsection{Statistical Analyses}

Age, gender and liver function tests of the patients were evaluated retrospectively and compared between the two groups. Pearson correlation coefficient was calculated between the variables. Student's t test was used to compare the two groups. Chi-square test was used for categorical variables.

\section{Results}

A total of 686 (342 female, 344 male) patients with T2DM were included in the study. There were 136 (58.6\%) male and 96 (41.4\%) female patients in the HBsAg positive group; the mean age of the group was $59.5 \pm 11.1$. There were $208(45.8 \%)$ male and $246(54.2 \%)$ female patients in the non-hepatitis B group. The mean age of the group was $50.55 \pm 11.9$ years. The proportion of male patients in the $\mathrm{HBs} \mathrm{Ag}$ positive group was higher than that of female patients (Table 1, Figure 1).

Table 1. Gender distribution of HBsAg positive and negative groups

\begin{tabular}{|c|c|c|c|c|c|}
\hline & & & & $3 \mathrm{sAg}$ & \\
\hline & & & Negative & Positive & Total \\
\hline & Male & $\mathrm{n}$ & 208 & 136 & 344 \\
\hline$\frac{1}{1}$ & & $\%$ within $\mathrm{HBsAg}$ & $45,8 \%$ & $58,6 \%$ & $50,1 \%$ \\
\hline $\bar{z}$ & Female & $\mathrm{n}$ & 246 & 96 & 342 \\
\hline 壱 & & $\%$ within $\mathrm{HBsAg}$ & $54,2 \%$ & $41,4 \%$ & $49,9 \%$ \\
\hline Total & & n & 454 & 232 & 686 \\
\hline & & $\%$ within $\mathrm{HBsAg}$ & $100,0 \%$ & $100,0 \%$ & $100,0 \%$ \\
\hline
\end{tabular}

HBsAg: Hepatitis B surface antigen, n: number 


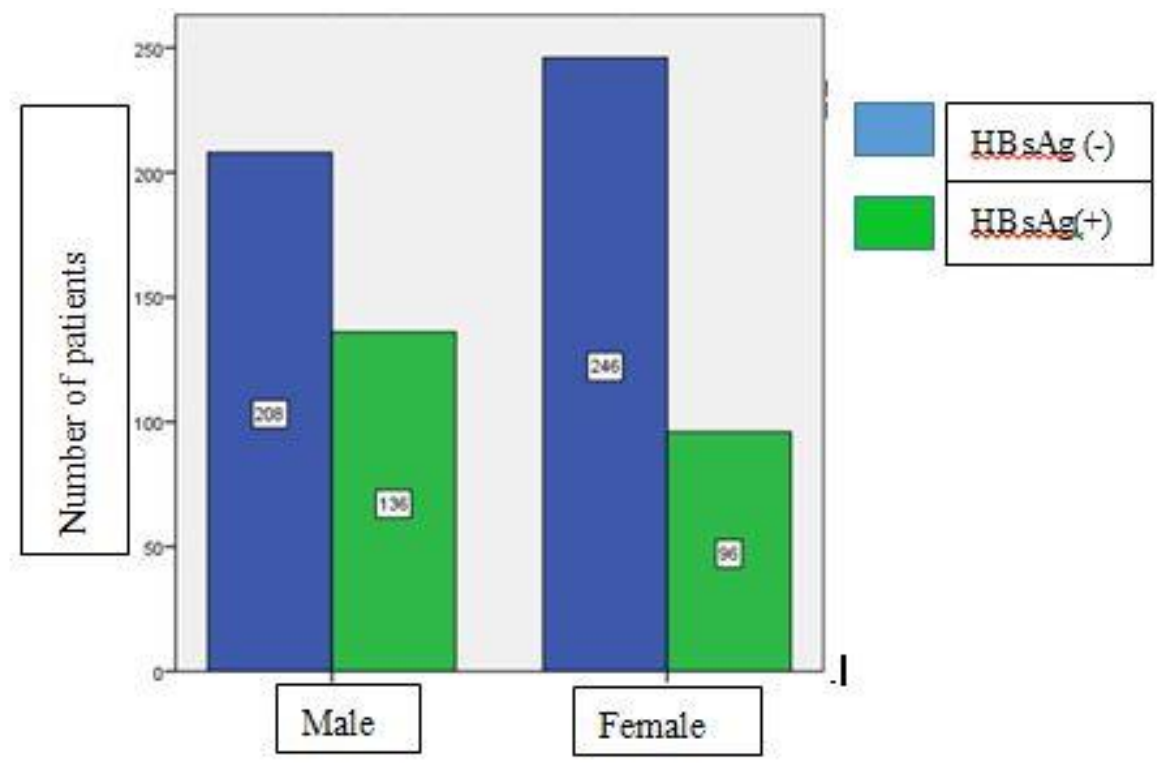

Figure 1. Distribution of HBsAg positive and negative groups by gender

In the HBsAg positive patient group; the relationship of HbsAg with ALT and AST was significant at $p$ $<0.05$ level. The relationship of Hbalc with ALT levels and age was statistically significant $(\mathrm{p}<0.01)$ in HBsAg positive group. No statistically significant difference was found between HBsAg and HbAlc in HB patients group (Table 2).

Table 2. Variables and statistical data in HBsAg positive T2DM patients

\begin{tabular}{|c|c|c|c|c|c|c|c|}
\hline & HbAlc & $\mathrm{HBeAg}$ & ALT & AST & Age & $\mathrm{HBsAg}$ \\
\hline \multirow[t]{3}{*}{ HbA1c } & Pearson Correlation & 1 & 0,054 & $0,214^{* *}$ & 0,116 & $-0,228^{* *}$ & 0,050 \\
\hline & Sig. (2-tailed) & & 0,416 & 0,001 & 0,083 & 0,001 & 0,459 \\
\hline & $\mathrm{N}$ & 225 & 225 & 223 & 225 & 225 & 225 \\
\hline \multirow[t]{3}{*}{$\mathrm{HBeAg}$} & Pearson Correlation & & 1 & 0,101 & $0,133^{*}$ & $-0,092$ & $-0,063$ \\
\hline & Sig. (2-tailed) & & & 0,131 & 0,047 & 0,170 & 0,347 \\
\hline & $\mathrm{N}$ & & & 223 & 225 & 225 & 225 \\
\hline \multirow[t]{3}{*}{ ALT } & Pearson Correlation & & & 1 & $0,878^{* *}$ & $-0,221^{* *}$ & $0,160^{*}$ \\
\hline & Sig. (2-tailed) & & & & 0,000 & 0,001 & 0,017 \\
\hline & $\mathrm{N}$ & & & & 223 & 223 & 223 \\
\hline \multirow[t]{3}{*}{ AST } & Pearson Correlation & & & & 1 & $-0,169^{*}$ & $0,170^{*}$ \\
\hline & Sig. (2-tailed) & & & & & 0,011 & 0,011 \\
\hline & $\mathrm{N}$ & & & & & 225 & 225 \\
\hline \multirow[t]{3}{*}{ Age } & Pearson Correlation & & & & & 1 & $-0,237^{* *}$ \\
\hline & Sig. (2-tailed) & & & & & & 0,000 \\
\hline & $\mathrm{N}$ & & & & & & 225 \\
\hline \multirow[t]{3}{*}{ HBsAg } & Pearson Correlation & & & & & & 1 \\
\hline & Sig. (2-tailed) & & & & & & \\
\hline & $\mathrm{N}$ & 225 & 225 & 223 & 225 & 225 & 225 \\
\hline
\end{tabular}

HbA1c: Hemoglobin A1c, HBeAg: Hepatitis B e Antigen, ALT: Alanine Aminotransferase AST: Aspartate Aminotransferase, HBsAg: Hepatitis B surface Antigen

The two groups were compared by Student's T test. The mean age of HBsAg positive patients was 
$54,61 \pm 11,381$ and the mean age of HBsAg negative patients was $59,44 \pm 14,043$. The HBsAg positive group patients were significantly younger than the other group $(\mathrm{t}=4.84, \mathrm{p}=0)$. Both $\mathrm{HBsAg}$ and $\mathrm{HBeAg}$ were significantly higher in HB patients, as expected in hepatitis B patients. There was no significant difference in AST and ALT levels between two groups. (Table 3).

Table 3. Comparison of data from two groups with Student's t test

\begin{tabular}{|c|c|c|c|c|c|}
\hline \multicolumn{5}{|c|}{ Group Statistics } & \multirow[t]{2}{*}{ Student's t } \\
\hline & HBsAg & Number & Mean & Std. Deviation & \\
\hline \multirow[t]{2}{*}{ Age } & Negative & 454 & 59,44 & 14,043 & \multirow{2}{*}{$\begin{array}{r}t=4,84 \\
P=0,000 \mathrm{~S}\end{array}$} \\
\hline & Positive & 232 & 54,61 & 11,381 & \\
\hline \multirow[t]{2}{*}{$\mathrm{HbA1c}$} & Negative & 454 & 8,92 & 2,20 & \multirow{2}{*}{$\begin{array}{r}t=1,15 \\
P=0,25 \mathrm{NS}\end{array}$} \\
\hline & Positive & 232 & 8,73 & 1,91 & \\
\hline \multirow{2}{*}{$\begin{array}{l}\text { HBsA } \\
\mathrm{g}\end{array}$} & Negative & 454 & 0,53 & 0,119 & \multirow{2}{*}{$\begin{array}{r}\mathrm{t}=-22,06 \\
\mathrm{P}=0,000 \mathrm{~S}\end{array}$} \\
\hline & Positive & 232 & 3286,89 & 2268,50 & \\
\hline \multirow{2}{*}{$\begin{array}{l}\mathrm{HBeA} \\
\mathrm{g}\end{array}$} & Negative & 454 & 0,110 & 0,033 & \multirow{2}{*}{$\begin{array}{r}t=-2,29 \\
P=0,020 \mathrm{~S}\end{array}$} \\
\hline & Positive & 232 & 18,94 & 125,05 & \\
\hline \multirow[t]{2}{*}{ ALT } & Negative & 447 & 55,12 & 132,586 & \multirow{2}{*}{$\begin{array}{r}t=-1,42 \\
P=0,15 \mathrm{NS}\end{array}$} \\
\hline & Positive & 230 & 74,43 & 183,202 & \\
\hline \multirow[t]{2}{*}{$\overline{\mathrm{AST}}$} & Negative & 454 & 41,44 & 81,185 & \multirow{2}{*}{$\begin{array}{r}\mathrm{t}=-1,24 \\
\mathrm{P}=0,21 \mathrm{NS}\end{array}$} \\
\hline & Positive & 232 & 50,62 & 109,470 & \\
\hline
\end{tabular}

HbA1c: Hemoglobin A1c, HBeAg: Hepatitis B e Antigen, ALT: Alanine Aminotransferase AST: Aspartate Aminotransferase, HBsAg: Hepatitis B surface Antigen

S: Statistically significant

NS: Statistically not-significant

\section{Discussion}

The liver plays an important and critical role in glucose metabolism. Therefore, hepatic part of glucose metabolism is adversely affected in liver diseases(Li-Ng, Tropp, Danoff, \& Bini, 2007). Glucose intolerance occurs in up to $80 \%$ of patients with chronic liver disease while the frequency of DM is found to be $30-60 \%$ (Blendea, Thompson, \& Malkani, 2010; García-Compean, Jaquez-Quintana, \& Maldonado-Garza, 2009). Advanced age, obesity, serious liver fibrosis and family history of diabetes have been identified as potential risk factors for the development of DM in patients with chronic hepatitis(Petit et al., 2001).

In diabetic patients, capillary and venous blood sampling procedures are frequently performed for regular blood glucose monitoring and biochemical examinations. Therefore, it was considered that HBV can be transmitted from patient to patient in diabetic patients, especially in the hospital environment. There was not any statistically significant relationship between T2DM and HB in current study. There are various studies about the relationship between hepatitis B and diabetes mellitus; some reveals associations while some reported no association. A study conducted in China reported that HB infection was detected among diabetic patients more than the normal population (Zhang et al., 2019). However, there are studies reporting that diabetes is not associated with hepatitis. A study from Brazil reported that low prevalence of HBV and high prevalence of hepatitis C virus (HCV) among T2DM patients (Villar et al., 2019). Huang et al. conducted a cross-sectional study about the association between HBV, HCV and T2DM prevalence among 9,932 participants in an endemic area for HBV and HCV infections in Taiwan. The authors reported that the prevalence of T2DM among HCV patients was significantly higher than HB patients and there wasn't any association between HBV and T2DM (Huang et al., 2007).

The proportion of males in HBsAg positive patients was higher than females. This finding is consistent with the literature. Hepatitis B has been reported to be more common in men than in women(MacLachlan \& Cowie, 2015). The relationship of HbsAg with ALT and AST was significant. Since hepatitis B is progressing with liver damage, liver enzymes are generally expected to correlate with antigenemia. HBV infection was reported to promote gluconeogenesis and the pentose phosphate pathway(Shi, Huang, \& Yang, 2016). This may explain the correlation of HbAlc with age and ALT elevation in HBsAg positive patients.

As a result, there was no significant relationship between HB and T2DM in current retrospective study including T2DM patients. 


\section{Acknowledgement}

The authors declare ne conflict of interest.

\section{References}

Blendea, M. C., Thompson, M. J., \& Malkani, S. (2010). Diabetes and Chronic Liver Disease: Etiology and Pitfalls in Monitoring. Clinical Diabetes, 28(4), 139-144. doi:10.2337/diaclin.28.4.139

Centers for Disease Control and Prevention. (2017). National Diabetes Statistics Report | Data \&amp; Statistics | Diabetes |CDC. Centers for Disease Control and Prevention, US Department of Health and Human Services; Atlanta. Retrieved from https://www.cdc.gov/diabetes/data/statistics/statistics-report.html

García-Compean, D., Jaquez-Quintana, J. O., \& Maldonado-Garza, H. (2009). Hepatogenous diabetes. Current views of an ancient problem. Annals of Hepatology, 8(1), 13-20.

Goyal, R., \& Jialal, I. (2019). Diabetes Mellitus Type 2. StatPearls. StatPearls Publishing. Retrieved from http://www.ncbi.nlm.nih.gov/pubmed/30020625

Huang, J.-F., Dai, C.-Y., Hwang, S.-J., Ho, C.-K., Hsiao, P.-J., Hsieh, M.-Y., ... Yu, M.-L. (2007). Hepatitis C Viremia Increases the Association With Type 2 Diabetes Mellitus in a Hepatitis B and C Endemic Area: An Epidemiological Link With Virological Implication. The American Journal of Gastroenterology, 102(6), 1237-1243. doi:10.1111/j.1572-0241.2007.01181.x

Li-Ng, M., Tropp, S., Danoff, A., \& Bini, E. J. (2007). Association between chronic hepatitis B virus infection and diabetes among Asian Americans and Pacific Islanders. Digestive and Liver Disease, 39(6), 549-556. doi:10.1016/J.DLD.2007.02.014

MacLachlan, J. H., \& Cowie, B. C. (2015). Hepatitis B virus epidemiology. Cold Spring Harbor Perspectives in Medicine, 5(5), a021410. doi:10.1101/cshperspect.a021410

Petit, J. M., Bour, J. B., Galland-Jos, C., Minello, A., Verges, B., Guiguet, M., ... Hillon, P. (2001). Risk factors for diabetes mellitus and early insulin resistance in chronic hepatitis C. Journal of Hepatology, 35(2), 279-83. doi:10.1016/s0168-8278(01)00143-x

Shi, Y.-X., Huang, C.-J., \& Yang, Z.-G. (2016). Impact of hepatitis B virus infection on hepatic metabolic signaling pathway. World Journal of Gastroenterology, 22(36), 8161-7. doi:10.3748/wjg.v22.i36.8161

Villar, L. M., Geloneze, B., Vasques, A. C. J., Pires, M. L. E., Miguel, J. C., Silva, E. F. da, ... Lampe, E. (2019). Prevalence of hepatitis B and hepatitis $\mathrm{C}$ among diabetes mellitus type 2 individuals. PLoS ONE, 14(2), e0211193. doi:10.1371/JOURNAL.PONE.0211193

World Health Organisation. (2019). Hepatitis B. Retrieved from https://www.who.int/newsroom/fact-sheets/detail/hepatitis-b

Zhang, X., Zhu, X., Ji, Y., Li, H., Hou, F., Xiao, C., \& Yuan, P. (2019). Increased risk of hepatitis B virus infection amongst individuals with diabetes mellitus. Bioscience Reports, 39(3), BSR20181715. doi:10.1042/BSR20181715 